OPEN ACCESS

Edited by:

Jie Hu,

The Ohio State University,

United States

Reviewed by:

Ruizhi Zhao,

Anthem, United States

Shouying Chen,

Public Health College, Hebei

University, China

*Correspondence:

Shaopeng $X u$

xsplzy@163.com

Qing Yang

yq1963884@sina.com

Jinghua Wang

jhw8799@yahoo.com

${ }^{\dagger}$ These authors have contributed equally to this work

Specialty section:

This article was submitted to

Epidemiology,

a section of the journal

Frontiers in Public Health

Received: 12 August 2019

Accepted: 27 July 2020

Published: 10 September 2020

Citation:

Lin Q, Liu J, Xu S, Ning X, Tu J, Yang Q and Wang $J(2020)$ Epidemiological Features of Glycemic Levels and Relative Determinants at Different Altitudes Among Tibetans in China: A Cross-Sectional Population-Based Study. Front. Public Health 8:472. doi: 10.3389/fpubh.2020.00472

\section{Epidemiological Features of Glycemic Levels and Relative Determinants at Different Altitudes Among Tibetans in China: A Cross-Sectional Population-Based Study}

\author{
Qiuxing Lin ${ }^{1,2,3+}$, Jie Liu ${ }^{1,2,3+}$, Shaopeng $\mathrm{Xu}^{4 *}$, Xianjia Ning ${ }^{1,2,3}$, Jun Tu ${ }^{1,2,3}$, Qing Yang ${ }^{4 *}$ and \\ Jinghua Wang ${ }^{1,2,3 *}$
}

${ }^{1}$ Department of Neurology, Tianjin Medical University General Hospital, Tianjin, China, ${ }^{2}$ Laboratory of Epidemiology, Tianjin Neurological Institute, Tianjin, China, ${ }^{3}$ Key Laboratory of Post-Neuroinjury Neuro-repair and Regeneration in Central Nervous System, Ministry of Education and Tianjin City, Tianjin Neurological Institute, Tianjin, China, ${ }^{4}$ Department of Cardiology, Tianjin Medical University General Hospital, Tianjin, China

Risk factors associated with diabetes mellitus have been widely researched worldwide, but the determinants of glycemic levels among Tibetans in China are currently unclear We thus aimed to determine the relationship between altitude and glycemic levels and to identify factors associated with glycemic levels among Tibetans in China. In 2011, a total of 1,659 Tibetans (aged $\geq 18$ years) from Changdu, China, were enrolled to this cross-sectional research. Potential factors associated with postprandial glucose (PPG), fasting plasma glucose (FPG), and insulin (INS) levels were assessed. FPG and PPG levels increased with age and total cholesterol (TC) level. In addition, FPG levels were higher among patients with rural residence and hypertension, while PPG levels increased with increasing BMI. INS levels increased with residence, lower education, higher BMI, and higher TG levels and decreased with higher altitude and TC levels. Moreover, risk factors for FPG, PPG, and INS differed in those residing at a higher altitude. These findings identify several important risk factors that affect glycemic levels and may be used to develop effective strategies for metabolic disease prevention among populations in high-altitude areas. Furthermore, these findings suggest that it is necessary to formulate a standard for PPG, FPG, and INS in high-altitude areas.

Keywords: altitude, glycemia, epidemiology, risk factors, Tibetans

\section{INTRODUCTION}

Diabetes mellitus (DM) is one of the most common chronic diseases worldwide, and it continues to increase in prevalence and disease burden (1). Since 1980, the number of adults with diabetes has quadrupled in the world. The burden of DM, both in terms of economic burden and prevalence, has increased more quickly in developing countries than in developed countries (2). In the past two decades, the prevalence of type 2 (T2) DM in China has risen rapidly, and it has become the country with the highest prevalence and number of patients $(2,3)$. 
A few studies have demonstrated the epidemiology of DM and its major risk factors at different altitudes. A recent study reported an odds ratio (OR) of 0.88 for T2 DM among those living $1,500-3,500 \mathrm{~m}$ above sea level (4). In addition, some studies reported that residents in high-altitude areas have lower glycemic levels than residents in sea-level areas (5-7).

However, these studies were conducted in populations living at the same altitudes and did not include the influence of ethnic background. Furthermore, some laboratory tests were not included in these studies. Thus, the influence of altitude on glycemic levels among Tibetans, including lamas, residing at different altitudes is unclear.

We thus conducted a population-based survey among Tibetans residing at different altitudes in China. The purpose of this study was to evaluate the relationship among various factors, particularly altitude, on glycemic levels.

\section{MATERIALS AND METHODS}

\section{Study Population}

This study design has been described previously (8). The survey was conducted from September 2010 to June 2011. The study population was recruited from the Changdu region of the Tibet Autonomous Region of China. There are 11 counties, including 142 townships and 11 central temples, in the Changdu region, with altitudes between 3,200 and $4,500 \mathrm{~m}$. More than $95 \%$ of residents are Tibetan.

A total of 1,960 people were selected and invited to participate in the survey. A total of 1,766 people completed the study. The overall response rate was $90.1 \%$. Of those who responded, 1,659 Tibetans were included, after excluding 134 residents without complete demographic data and 167 residents of other ethnicities.

A representative sample of the Tibetan population in China was selected using the multistage (altitude-countytownship-village) stratified cluster random sampling method. First, according to different altitude levels $(<3,500 \mathrm{~m}$ [lower altitude], 3,500-4,000 $\mathrm{m}$ [moderate altitude], and $>4,000 \mathrm{~m}$ [high altitude]), all 11 counties in Changdu were stratified into three groups. Second, one county was selected from each altitude group, which included three counties. Third, four townships from each selected county were selected, for a total of 12 townships. Fourth, three villages or neighborhoods were selected from each selected township. Finally, 36 villages or neighborhoods were selected. Moreover, in each county, we selected one central temple; all qualified lamas were recruited in this study. Finally, all residents aged $\geq 18$ years from the selected 31 villages, 5 neighborhoods, and 3 central temples were recruited in this study.

The ethics committee of Changdu Region People's Hospital, Tibet approved the study, and written informed consent was obtained from all participants during recruitment. All methods were performed in accordance with the relevant guidelines and regulations.

\section{Information Evaluated in This Study}

In 2011, 1,659 Tibetan adults aged $\geq 18$ years were recruited to the present study in Changdu, China. Data collection included survey interviews, clinical measurements, and laboratory tests. Standard questionnaires were conducted by trained researchers to collect information about demographic characteristics, anthropometry, personal and family medical history, educational, and lifestyle risk factors including hypertension, obesity, alcohol consumption, and current smoking. The physical examinations and laboratory tests were completed by professional. The relationship of glycemic level with geographic altitude and demographic characteristics was assessed.

Detailed information was collected with regard to sex, age group (18-34, 35-44, 45-54, 55-64, $\geq 65$ years), education level $(0,1-6,>6$ years), socioeconomic status (yearly family income: $<800,800-1,600, \geq 1,601$ USD/year), cigarette smoking (no, yes), butter tea consumption (no, yes), alcohol use (no, yes), residence (rural/pastoral area, urban area, temple), and altitude $(<3,500, \geq 3,500 \mathrm{~m})$. In addition to blood pressure measurement, physical examinations also included body height, weight, and circumferences of the waist, hip, and abdomen. Moreover,

TABLE 1 | The demographic characteristics of participants in Tibetans.

\begin{tabular}{|c|c|c|c|}
\hline Characteristics & Men $(n=822)$ & Women $(n=837)$ & Total $(n=1,659$ \\
\hline Age, years, means (SD) & $41.45(15.01)$ & $46.51(15.05)$ & $44.00(15.24)$ \\
\hline \multicolumn{4}{|l|}{ Age group, $n(\%):$} \\
\hline $18-34$ yrs & 299 (36.4) & $194(23.2)$ & $493(29.7)$ \\
\hline $35-44$ yrs & $194(23.6)$ & $193(23.1)$ & $387(23.3)$ \\
\hline $45-54$ yrs & $161(19.6)$ & $201(24.0)$ & $362(21.8)$ \\
\hline $55-64$ yrs & $105(12.8)$ & $138(16.5)$ & $243(14.6)$ \\
\hline$\geq 65 \mathrm{yrs}$ & $63(7.7)$ & $111(13.3)$ & $174(10.5)$ \\
\hline \multicolumn{4}{|l|}{ Education, $n(\%)$ : } \\
\hline 0 yrs & $394(47.9)$ & $607(72.5)$ & $1,001(60.3)$ \\
\hline $1-6 \mathrm{yrs}$ & $330(40.1)$ & $102(12.2)$ & $432(26.0)$ \\
\hline$>6 \mathrm{yrs}$ & $98(11.0)$ & $128(15.3)$ & $226(13.6)$ \\
\hline \multicolumn{4}{|l|}{ Residence, $n(\%):$} \\
\hline Rural/pastoral area & $353(43.0)$ & $586(70.0)$ & $936(56.4)$ \\
\hline Urban & $144(17.5)$ & $251(30.0)$ & $395(23.7)$ \\
\hline Temple & 325 (39.5) & $3(0.4)$ & $328(19.8)$ \\
\hline \multicolumn{4}{|l|}{ Altitude, meter, $\boldsymbol{n}(\%)$} \\
\hline$<3,500$ & $444(54.0)$ & $463(55.3)$ & $907(54.7)$ \\
\hline $3,500-4,000$ & $266(32.4)$ & 334 (39.9) & $600(36.2)$ \\
\hline$>4,000$ & $112(13.6)$ & $40(4.8)$ & $152(9.1)$ \\
\hline \multicolumn{4}{|l|}{ Family income yearly, USD: } \\
\hline$<800$ & $508(61.8)$ & $436(52.1)$ & $944(56.9)$ \\
\hline $800-1,600$ & $145(17.6)$ & $162(19.4)$ & 307 (18.5) \\
\hline$\geq 1,601$ & $169(20.6)$ & $239(28.5)$ & $408(24.6)$ \\
\hline Current smoking, $n(\%)$ & $73(11.2)$ & $6(0.9)$ & $79(6.1)$ \\
\hline Alcohol consumption, $n(\%)$ & $48(7.4)$ & $67(10.5)$ & $115(8.9)$ \\
\hline FPG, mmol/L, means (SD) & $5.12(1.77)$ & $5.13(1.52)$ & $5.12(1.65)$ \\
\hline PPG, mmol/L, means (SD) & $5.89(3.31)$ & $5.97(2.80)$ & $5.93(3.07)$ \\
\hline INS, mmol/L, means (SD) & $8.79(6.31)$ & $8.75(5.86)$ & $8.77(6.10)$ \\
\hline
\end{tabular}


fasting plasma glucose (FPG), postprandial glucose (PPG), and insulin (INS) levels were tested; Blood lipid-related testing [total cholesterol (TC), triglycerides (TG), low-density lipoproteincholesterol (LDL-C), and high-density lipoprotein-cholesterol (HDL-C levels)] was also conducted.

\section{Definitions}

The normal group was defined as having a range of 3.9-6.1 $\mathrm{mmol} / \mathrm{L}$ for FPG, $\leq 7.8 \mathrm{mmol} / \mathrm{L}$ for $2-\mathrm{h} \mathrm{PPG}$, and 35-145 $\mathrm{pmol} / \mathrm{L}$ for INS.

Hypertension was defined as an average systolic blood pressure (SBP) of $\geq 140 \mathrm{mmHg}$ and/or an average diastolic blood pressure (DBP) of $\geq 90 \mathrm{mmHg}$, or current use of any medication for treating hypertension within 2 weeks or any combination of the above (9).

Body mass index (BMI) was calculated as the ratio of weight to height squared $\left(\mathrm{kg} / \mathrm{m}^{2}\right)$. According to standard criteria in Chinese adults, participants with a BMI $\geq 24$ and $<28 \mathrm{~kg} / \mathrm{m}^{2}$ were classified as overweight, and those with a BMI $\geq 28 \mathrm{~kg} / \mathrm{m}^{2}$ were classified as obese (10).

\section{Data Collection}

Data collection was conducted by face-to-face interviews in the community health stations, and physical examinations were performed by investigators who underwent strict training by epidemiology professionals before the start of the study. A few participants completed the survey at home. A preordain standardized questionnaire was administered in this survey.

\section{Statistical Analysis}

Continuous variables are presented as means [standard deviations (SD)], and categorical variables are expressed as percentages $[95 \%$ confidence intervals (Cis)]. Categorical variables were analyzed using the chi-squared test. The rates of influencing factors, including hypertension, obesity, and smoking, were presented according to five age groups. The risk factors of FPG, PPG, and INS were analyzed by sex, age group, yearly family income, education level, residence, altitude, smoking, butter-tea consumption, and alcohol consumption in the univariate analysis. Determinants of FPG, PPG, and INS were assessed by multivariate linear regression analysis after adjustment for confounding factors that were statistically significant. Statistical significance was defined as a two-tailed $P$ $<0.05$. Statistical analyses were undertaken using the computer software SPSS (version 15.0 for Windows; SPSS, Chicago, IL, USA).

\section{RESULTS}

\section{Descriptive Characteristics of Participants}

A total of 1,659 people ( 822 men: $49.5 \%$; 837 women: $49.5 \%)$ were selected for this cross-sectional study; $60 \%$ of participants were $<45$ years of age. In addition, $56.4 \%$ of participants resided in $\mathrm{rural} /$ pastoral areas, and $54.7 \%$ lived at an altitude of $<3,500 \mathrm{~m}$. The average education level was low, with a relative high overall illiteracy rate of $60 \%$. In addition, $56.9 \%$ participants had a yearly family income of $<800$ USD/year. Moreover, $6.1 \%$ of participants smoked, and $8.9 \%$ of participants consumed alcohol. The average levels of FPG, PPG, and INS were 5.12, 5.93, and $8.77 \mathrm{mmol} / \mathrm{L}$, respectively (Table $\mathbf{1}$ ).

\section{Factors Associated With Blood Glucose Levels in the Univariate Analysis}

FPG, PPG, and INS levels were associated with residence, hypertension, and BMI; furthermore, FPG and PPG levels

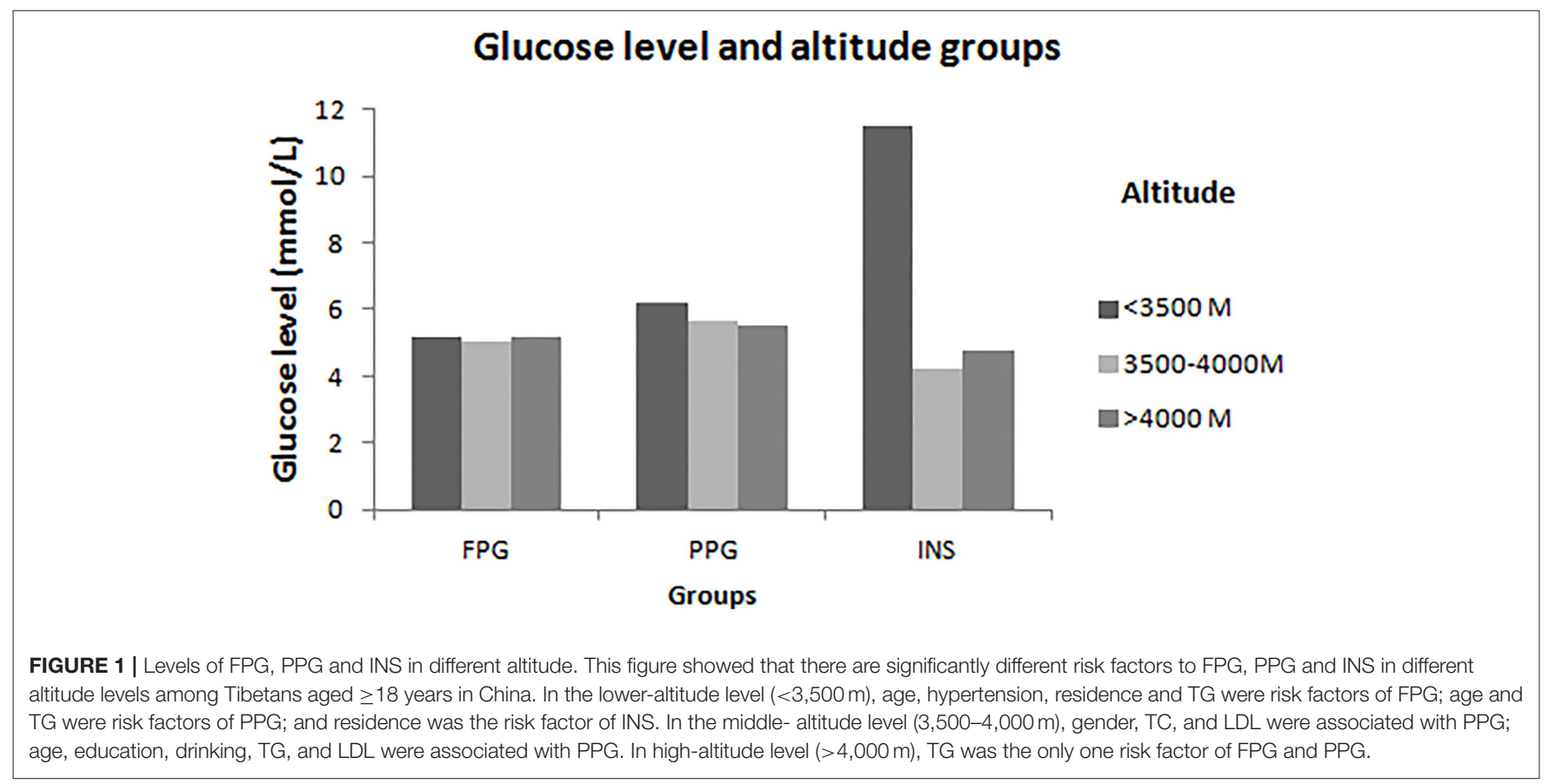


increased with age group. PPG and INS levels were associated with altitude (Figure 1). INS levels were 2.41-fold higher among low-altitude residents than among high-altitude residents. In addition, alcohol consumption significantly increased PPG levels by 1.12-fold compared to non-alcohol consumption. INS levels were also related to education level, smoking, and consuming butter tea (Table 2). Moreover, FPG and PPG levels were increased with increasing TC,

TABLE 2 | Levels of blood glucose in the different groups by demography.

\begin{tabular}{|c|c|c|c|}
\hline Characteristics & FPG & PPG & INS \\
\hline Gender: & 0.897 & 0.645 & 0.934 \\
\hline Men & $5.12(1.77)$ & 5.89 (3.31) & $8.79(6.31)$ \\
\hline Women & $5.13(1.52)$ & $5.97(2.80)$ & $8.75(5.86)$ \\
\hline Age group: & $<0.001$ & $<0.001$ & 0.141 \\
\hline $18-34$ yrs & $4.73(0.69)$ & $5.02(1.41)$ & $7.90(5.07)$ \\
\hline $35-44$ yrs & $5.00(1.11)$ & $5.66(2.27)$ & $9.41(7.15)$ \\
\hline $45-54$ yrs & $5.46(2.65)$ & $6.44(4.17)$ & $8.51(4.93)$ \\
\hline $55-64$ yrs & $5.58(2.03)$ & $7.22(4.17)$ & $10.04(8.01)$ \\
\hline $65-74$ yrs & $5.37(1.26)$ & 6.69 (3.03) & $8.64(4.80)$ \\
\hline Education: & 0.378 & 0.746 & $<0.001$ \\
\hline $0 \mathrm{yrs}$ & $5.10(1.44)$ & $5.91(2.71)$ & $7.53(6.40)$ \\
\hline $1-6 \mathrm{yrs}$ & $5.10(1.97)$ & $5.90(3.56)$ & $8.81(5.85)$ \\
\hline$>6 \mathrm{yrs}$ & $5.28(1.83)$ & $6.10(3.48)$ & $11.10(5.12)$ \\
\hline Residence: & $<0.001$ & $<0.001$ & $<0.001$ \\
\hline Rural/pastoral area & $5.10(1.08)$ & $5.88(2.49)$ & $3.75(2.60)$ \\
\hline Urban & $5.45(2.36)$ & $6.52(4.00)$ & $11.04(5.36)$ \\
\hline Temple & $4.79(1.78)$ & $5.36(3.02)$ & $8.77(7.22)$ \\
\hline Altitude: & 0.708 & 0.007 & $<0.001$ \\
\hline$<3,500 \mathrm{~m}$ & $5.15(1.94)$ & $6.18(3.44)$ & 11.53 (5.96) \\
\hline $3,500-4,000 \mathrm{~m}$ & $5.07(0.84)$ & $5.66(1.97)$ & $4.23(2.92)$ \\
\hline$>4,000 \mathrm{~m}$ & $5.16(2.14)$ & $5.53(3.86)$ & $4.78(3.00)$ \\
\hline Family income yearly: & 0.107 & 0.008 & 0.064 \\
\hline$<800$ USD & $5.08(1.68)$ & $5.72(3.06)$ & $9.58(6.71)$ \\
\hline $800-1,600$ USD & $5.04(1.70)$ & $5.98(2.38)$ & $8.48(5.54)$ \\
\hline$>1,600$ USD & $5.29(1.56)$ & $6.37(3.47)$ & $8.05(5.65)$ \\
\hline Hypertension: & $<0.001$ & $<0.001$ & $<0.001$ \\
\hline Yes & 5.35 (1.98) & $3.39(3.57)$ & $9.56(6.18)$ \\
\hline No & $4.73(0.70)$ & $5.14(1.61)$ & $7.37(4.83)$ \\
\hline BMI groups: & $<0.001$ & $<0.001$ & $<0.001$ \\
\hline Normal & $4.96(1.25)$ & $5.48(2.11)$ & $6.88(4.48)$ \\
\hline Over weight & $5.28(1.42)$ & $6.40(3.43)$ & $10.17(5.42)$ \\
\hline Obesity & $5.57(2.83)$ & $7.12(6.86)$ & $12.42(8.01)$ \\
\hline Current smoking & 0.505 & 0.542 & 0.012 \\
\hline Yes & $5.00(1.00)$ & $5.73(2.55)$ & $11.14(5.90)$ \\
\hline No & $5.13(1.69)$ & $5.95(3.10)$ & $8.55(6.07)$ \\
\hline Alcohol consumption & 0.172 & 0.001 & 0.064 \\
\hline Yes & $5.32(1.26)$ & 6.81 (3.02) & $7.35(5.52)$ \\
\hline No & $5.10(1.69)$ & $5.84(3.06)$ & $8.97(6.15)$ \\
\hline Butter tea consumption & 0.576 & 0.783 & 0.028 \\
\hline Yes & $5.13(1.66)$ & $5.93(3.09)$ & $8.61(6.16)$ \\
\hline No & $5.00(1.24)$ & $6.05(2.55)$ & $11.18(4.49)$ \\
\hline
\end{tabular}

TG, and LDL; INS was inversely proportional to LDL (Table 3).

\section{Risk Factors for High FPG, PPG, and INS}

Table 4 shows that age group, residence, hypertension, and TG level were significantly associated with FPG among Tibetans aged $\geq 18$ years in the multivariate linear regression analysis, with standard partial regression coefficient $(\beta)$ [95\% confidence intervals (CIs)] of $0.09(0.02,0.17 ; P=0.020)$ for age group, $-0.27(-0.42,-0.12 ; P<0.001)$ for residence, $0.27(0.07,0.48$; $P=0.010)$ for hypertension, and $0.29(0.20,0.38 ; P<0.001)$ for higher TG levels after adjustment for confounding factors. Age group, BMI group, and TG were also risk factors for PPG, with $\beta$ values (95\% CIs) of $0.33(0.19,0.47 ; P<0.001)$ for age group, $0.45(0.22,0.68 ; P<0.001)$ for BMI group, and $0.46(0.29$, 0.62; $P<0.001)$ for higher TG levels. Furthermore, residence, altitude group, education, BMI group, and TC and TG levels were risk factors for high INS levels. The corresponding $\beta$ values (95\% CIs) of INS were $1.23(0.41,2.06 ; P=0.004)$ for residence group, $-4.39(-5.39,-3.39 ; P<0.001)$ for altitude group, 0.68 $(0.07,1.29 ; P=0.030)$ for education group, and 2.14 (1.51, 2.77; $P<0.001)$ for BMI group. Moreover, the corresponding $\beta$ values (95\% CIs) of INS were $-0.64(-1.20,0.78 ; P=0.026)$ and 0.57 $(0.07,1.06 ; P=0.024)$ for TC and TG levels, respectively.

Based on the interaction results, we did a multivariate analysis according to different altitude groups. In the low altitude group, FPG levels increased in those individuals with high TG level; but decreased by $0.309 \mathrm{mmol} / \mathrm{L}$ in individuals lived in rural/pastoral area than those lived in urban and decreased by $0.309 \mathrm{mmol} / \mathrm{L}$ in individuals lived in temple than those lived in rural/pastoral area $(\beta,-0.309 ; 95 \% \mathrm{CI},-0.514$ to $-0.105 ; P<0.001)$. Moreover, elevated TG level associated with increased FPG $(\beta, 0.251 ; 95 \%$ CI, 0.137-0.365; $P<0.001)$ and PPG $(\beta, 0.495$; 95\% CI, $0.284-$ $0.705 ; P<0.001)$. In the $3,500-4,000 \mathrm{~m}$ group, each $1 \mathrm{mmol} / \mathrm{L}$ increasing with TG levels resulted in $0.295 \mathrm{mmol} / \mathrm{L}$ increase of PPG $(\beta, 0.295 ; 95 \%$ CI, $0.054-0.537 ; P=0.017)$. However, in the $>4,000-\mathrm{m}$ group, each $1 \mathrm{mmol} / \mathrm{L}$ increase of TG level, FPG levels increased by $0.907 \mathrm{mmol} / \mathrm{L}(\beta, 0.907 ; 95 \% \mathrm{CI}, 0.111-1.703 ; P=$ $0.026)$, while $\mathrm{PPG}$ levels increased by $1.703 \mathrm{mmol} / \mathrm{L}(\beta, 1.703$; 95\% CI, 0.283-3.123; $P=0.019$ ) (Table 5).

\section{DISCUSSION}

This is the first study to report factors associated with glycemic levels among Tibetans aged $\geq 18$ years in China. The results of the present study reveal that altitude was an important factor related to glycemic levels. Furthermore, there were significantly different risk factors for FPG, PPG, and INS levels at different altitude levels. At lower altitude $(<3,500 \mathrm{~m})$, age, hypertension, residence, and TG levels were risk factors for FPG levels; age and TG levels were risk factors for PPG levels; and residence was a risk factor for INS levels. At moderate altitude (3,500-4,000 m), sex, TC, and LDL were risk factors for PPG levels; and age, education, drinking, and TG and LDL levels were risk factors for PPG levels. At high altitude $(>4,000 \mathrm{~m})$, TG levels were the only risk factor for FPG and PPG levels; in contrast, after adjusting for other 
TABLE 3 | The association of different glucose level with measurements of lipids in the univariate analysis.

\begin{tabular}{|c|c|c|c|c|c|c|}
\hline \multirow[t]{2}{*}{ Risk factors } & \multicolumn{2}{|l|}{ FPG } & \multicolumn{2}{|l|}{ PPG } & \multicolumn{2}{|l|}{ INS } \\
\hline & $\beta(95 \% \mathrm{Cl})$ & $\boldsymbol{P}$ & $\beta(95 \% \mathrm{Cl})$ & $P$ & $\beta(95 \% \mathrm{Cl})$ & $\boldsymbol{P}$ \\
\hline TC & $0.321(0.240,0.403)$ & $<0.001$ & $0.647(0.494,0.801)$ & $<0.001$ & $0.717(0.190,1.244)$ & 0.008 \\
\hline $\mathrm{TG}$ & $0.377(0.302,0.451)$ & $<0.001$ & $0.642(0.502,0.781)$ & $<0.001$ & $1.247(0.766,1.728)$ & $<0.001$ \\
\hline HDL-C & $0.055(-0.149,0.260)$ & 0.596 & $-0.013(-0.398,0.373)$ & 0.949 & $2.188(0.867,3.509)$ & 0.001 \\
\hline LDL-C & $0.251(0.137,0.365)$ & $<0.001$ & $0.597(0.383,0.811)$ & $<0.001$ & $-0.652(-1.406,0.102)$ & 0.090 \\
\hline
\end{tabular}

TABLE 4 | Determinants of FPG, PPG, and INS among Tibetans aged $\geq 18$ years using multivariate regression analysis.

\begin{tabular}{|c|c|c|c|c|c|c|}
\hline \multirow[t]{2}{*}{ Category } & \multicolumn{2}{|l|}{ FPG } & \multicolumn{2}{|c|}{ PPG } & \multicolumn{2}{|l|}{ INS } \\
\hline & $\beta(95 \% \mathrm{Cl})$ & $\boldsymbol{P}$ & $\beta(95 \% \mathrm{Cl})$ & $P$ & $\beta(95 \% \mathrm{Cl})$ & $P$ \\
\hline Age group & $0.09(0.02,0.17)$ & 0.020 & $0.33(0.19,0.47)$ & $<0.001$ & - & - \\
\hline Altitude group & - & - & $-0.01(-0.29,0.27)$ & 0.948 & $-4.39(-5.39,-3.39)$ & $<0.001$ \\
\hline Residence & $-0.27(-0.42,-0.12)$ & $<0.001$ & $-0.24(-0.54,0.07)$ & 0.135 & $1.23(0.41,2.06)$ & 0.004 \\
\hline Family income yearly & - & - & $0.07(-0.14,0.29)$ & 0.518 & - & - \\
\hline Education & - & - & - & - & $0.68(0.07,1.29)$ & 0.030 \\
\hline Hypertension & $0.27(0.07,0.48)$ & 0.010 & $0.35(-0.03,0.74)$ & 0.073 & $-0.22(-1.1,1.0)$ & 0.692 \\
\hline BMl group & $0.118(-0.01,0.24)$ & 0.060 & $0.45(0.22,0.68)$ & $<0.001$ & $2.14(1.51,2.77)$ & $<0.001$ \\
\hline Current smoking & - & - & - & - & $1.17(-0.63,2.87)$ & 0.211 \\
\hline Alcohol consumption & - & - & $0.38(-0.20,0.96)$ & 0.202 & - & - \\
\hline TC & $0.15(-0.03,0.33)$ & 0.108 & $0.03(-0.34,0.34)$ & 0.985 & $-0.64(-1.20,0.78)$ & 0.026 \\
\hline TG & $0.29(0.20,0.38)$ & $<0.001$ & $0.46(0.29,0.62)$ & $<0.001$ & $0.57(0.07,1.06)$ & 0.024 \\
\hline HDL-C & - & - & - & - & $0.67(-0.78,2.11)$ & 0.366 \\
\hline LDL-C & $-0.06(-0.29,0.17)$ & 0.590 & $0.23(-0.20,0.65)$ & 0.295 & - & - \\
\hline
\end{tabular}

conventional risk factors, there were no risk factors for INS levels at moderate or high altitude.

Risk factors for FGP, PPG, and INS levels at lower altitude $(<3,500 \mathrm{~m})$ were similar to those of previous studies reporting risk factors at sea level. However, the current study found fewer risk factors in the study population of Tibetans in China. In previous studies, age, obesity, hypertension, TC levels, TG levels, living in low-income areas, alcohol consumption were confirmed as risk factors for DM at sea level (11-14). With regard to age, FPG levels increase with age, with a $0.07-\mathrm{mmol} / \mathrm{L}$ increase in as a risk factor FPG levels each decade of life (11). Poor recognition of disease prevention, unawareness of the diabetes and relatively limited medical resources in rural areas probably was the reason of regional difference. In the same time, more than $50 \%$ of DM patients had hypertension $(12,13)$. With regard to residential area as a risk factor, the prevalence of DM in rural areas is higher than that in urban areas in north China (15). These regional differences are likely explained by poor recognition of disease prevention, unawareness of DM, and relatively limited medical resources in rural areas.

There is compelling evidence that populations living at an altitude of 3,000-4,500 $\mathrm{m}$ have lower FPG levels than those living below $500 \mathrm{~m}$ (16-20). For example, residents living at 3,200 m had lower glycemic levels compared with those living at sea level (5). In addition, a study reported that median FPG level was 81.6 $\mathrm{mg} / \mathrm{dL}$ for men living above 3,000 $\mathrm{m}$ and was significantly higher than that in non-pregnant adult women, who had a median FPG level of $71.7 \mathrm{mg} / \mathrm{dL}$ (19); thus, there are also sex differences in FPG levels at this altitude. Moreover, sex was closely related to the postprandial glucose response in patients with T2 DM in lowaltitude (14). Thus, the relationship between sex and FPG in the present study is consistent with findings of previous studies.

It is noteworthy that risk factors for high FPG levels in residents living at moderate altitude $(3,500-4,000 \mathrm{~m})$ included sex and TC levels. Moreover, age, education, and TC were negatively related with PPG levels in residents living at moderate altitude. Furthermore, alcohol consumption was an independent risk factor for PPG, after adjusting for other conventional risk factors. This is consistent with previous research, which showed that excessive drinking was related to elevated FPG levels in adults aged 16-43 years (21). The relationship of alcohol consumption and the incidence of DM has been widely accepted, and alcohol consumption exhibits a U-shaped relationship with the risk of T2 DM $(22,23)$. There were no risk factors.

At high altitude $(>4,000 \mathrm{~m})$, TG levels were the only independent risk factor for FPG and PPG levels, after adjustment for other conventional risk factors.

According to above findings, it is evident that there are fewer risk factors for hyperglycemia in residents at increasing altitudes. However, as the study population were residents, these findings may not apply to the short-term effects of altitude on blood glucose levels. Fasting glucose levels of healthy people living at 
TABLE 5 | Determinants of FPG, PPG and INS at different altitude group.

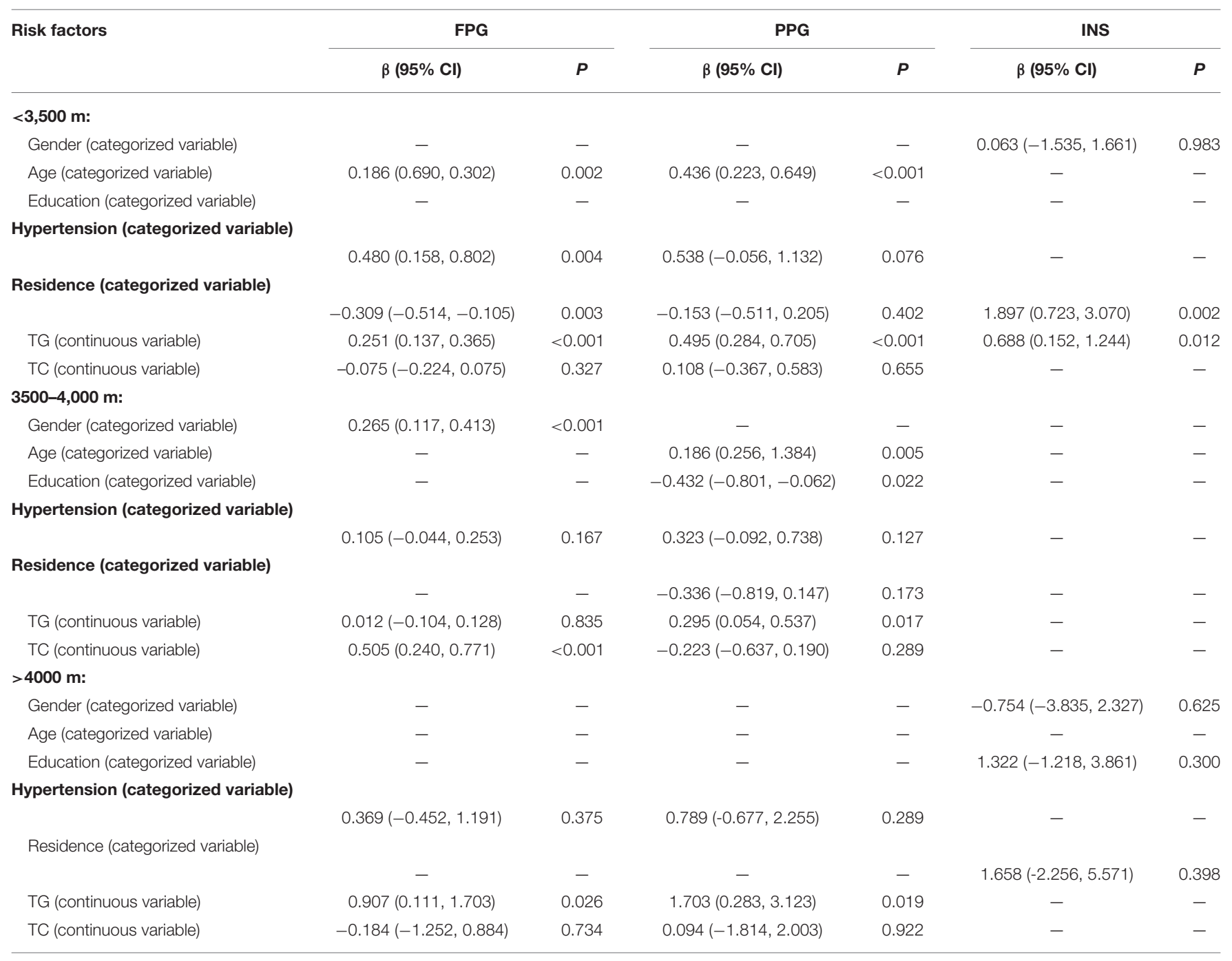

sea level exposed to very high altitude has been reported to increase, decrease, or remain unchanged (24-26). Moreover, a recent study reported that people have better glycemic control at higher altitudes (27). In contrast, another study reported no significant differences in fasting glycemia between low and high altitudes (28). Nonetheless, the present study in Tibetans reveals important insights regarding the effects of altitude on risk factors for high glycemic levels in residents.

There were several limitations in this study. First, the population was only selected from the Changdu region; however, the four-stage randomly stratified cluster sampling method was used to make the study population representative. Second, a lower altitude (closer to sea level) population was not included in this comparison, as all participants lived above $3,200 \mathrm{~m}$; however, the subgroup analyses were stratified by altitude $(<3,500$ and $\geq 3,500 \mathrm{~m})$. Third, dietary intake and physical activity were not considered in this study; however, some lifestyle factors, including smoking, alcohol consumption, and butter tea consumption were evaluated. Finally, we did not use hemoglobin A1c level as a biomarker of glycemia, and this may result in less stable findings regarding the glycemic state. Future studies should include a more stable indicator of glycemia.

This is the first study to report factors influencing glycemic level among Tibetans aged $\geq 18$ years in China. Risk factors differed by altitude levels among Tibetans in China. FPG levels were associated with age, hypertension, rural residence, and TG levels in residents at lower altitude $(<3,500 \mathrm{~m})$; with sex, TC levels in residents at moderate altitude $(3,500-4,000 \mathrm{~m})$; and only with TG levels in residents at high altitude $(>4,000 \mathrm{~m})$. Similarly, PPG levels were associated with age and TG levels at lower altitude $(<3,500 \mathrm{~m})$; with age, education, and TG levels at moderate altitude $(3,500-4,000 \mathrm{~m})$; but only TG level at high altitude $(>4,000 \mathrm{~m})$. Moreover, INS levels were associated with residence and TG levels only at lower altitude $(<3,500 \mathrm{~m})$. These findings suggest that management of blood glucose levels should be approached differently according to different altitude levels. 


\section{DATA AVAILABILITY STATEMENT}

All datasets generated for this study are included in the article/supplementary material.

\section{ETHICS STATEMENT}

The studies involving human participants were reviewed and approved by the ethics committee of Changdu Region People's Hospital. The patients/participants provided their written informed consent to participate in this study.

\section{REFERENCES}

1. Shaw JE, Sicree RA, Zimmet PZ. Global estimates of the prevalence of diabetes for 2010 and 2030. Diabetes Res Clin Pract. (2010) 87:4-14. doi: 10.1016/j.diabres.2009.10.007

2. NCD Risk Factor Collaboration (NCD-RisC). Worldwide trends in diabetes since 1980: a pooled analysis of 751 population-based studies with 4.4 million participants. Lancet. (2016) 387:1513-30. doi: 10.1016/S0140-6736(16)00618-8

3. Bommer C, Heesemann E, Sagalova V, Manne-Goehler J, Atun $\mathrm{R}$, Bärnighausen $\mathrm{T}$, et al. The global economic burden of DM in adults aged 20-79: a cost-of-illiness study. Lancet DM Endocrinol. (2017) 5:423-30. doi: 10.1016/S2213-8587(17)30097-9

4. Woolcott OO, Castillo OA, Gutierrez C, Elashoff RM, Stefanovski D, Bergman $\mathrm{RN}$. Inverse association between diabetes and altitude: a cross-sectional study in the adult population of the United States. Obesity. (2014) 22:2080-90. doi: 10.1002/oby.20800

5. Castillo O, Woolcott OO, Gonzales E, Tello V, Tello L, Villarreal C, et al. Residents at high altitude show a lower glucose profile than sea-level residents throughout 12-hour blood continuous monitoring. High Alt Med Biol. (2007) 8:307-11. doi: 10.1089/ham.2007.8407

6. Calderón-Gerstein W. High altitude is not a risk factor for type 2 diabetes mellitus. Diabetes Res Clin Pract. (2017) 126:323-4. doi: 10.1016/j.diabres.2016.11.018

7. Seclen SN, Rosas ME, Arias AJ, Huayta E, Medina CA. Prevalence of diabetes and impaired fasting glucose in Peru: report from PERUDIAB, a national urban population-based longitudinal study. BMJ Open Diabetes Res Care. (2015) 3:e000110. doi: 10.1136/bmjdrc-2015-000110

8. $\mathrm{Xu} \mathrm{S}$, Jiayong $\mathrm{Z}$, Li B, Zhu $\mathrm{H}$, Chang $\mathrm{H}$, Shi $\mathrm{W}$, et al. Prevalence and clustering of cardiovascular disease risk factors among tibetan adults in china: a population-based study. PLOS ONE. (2015) 10:e0129966. doi: 10.1371/journal.pone.0129966

9. Chobanian AV, Bakris GL, Black HR, Cushman WC, Green LA, Izzo $\mathrm{JL} \mathrm{Jr}$, et al. The seventh report of the joint national committee on prevention, detection, evaluation, and treatment of high blood pressure: the JNC 7 report. JAMA. (2003) 289:2560-72. doi: 10.1001/jama.289. 19.2560

10. Disease control, Ministry of Health of the People's Republic of China. The Guidelines of Chinese Adult Overweight and Obesity Prevention and Control. Beijing: People's Medical Publishing House (2006).

11. Danaei G, Finucane MM, Lu Y, Singh GM, Cowan MJ, Paciorek CJ, et al. National, regional, and global trends in fasting plasma glucose and diabetes prevalence since 1980: systematic analysis of health examination surveys and epidemiological studies with 370 country-years and $2 \cdot 7$ million participants. Lancet. (2011) 378:31-40. doi: 10.1016/S0140-6736(11)6 0679-X

12. Sowers JR, Epstein M, Frohlich ED. Diabetes, hypertension, and cardiovascular disease: an update. Hypertension. (2001) 37:1053-9. doi: 10.1161/01.HYP.37.4.1053

13. Sowers JR. Diabetes mellitus and vascular disease. Hypertension. (2013) 61:943-7. doi: 10.1161/HYPERTENSIONAHA.111.00612

\section{AUTHOR CONTRIBUTIONS}

JW, QY, and SX were involved in conception and design, data collection, data interpretation, and critical review for this article. JW was involved in data analysis for this article. QL and JL were involved in manuscript drafting. QL, JL, SX, XN, JT, QY, and JW were involved in data collection, case diagnosis, and confirmation for this article. All authors reviewed the manuscript.

\section{ACKNOWLEDGMENTS}

We thank all participants in Tianjin Brain Study.

14. Diaf M, Khaled BM, Habib HH, Belbraoued S. Effect of gender and body weight on postprandial glucose and lipid metabolism in adults with Type 2 diabetes. JNMA J Nepal Med Assoc. (2014) 52:866-77. doi: $10.31729 /$ jnma.2707

15. Hu Y, Teng W, Liu L, Chen K, Liu L, Hua R, et al. Prevalence and risk factors of diabetes and diabetic retinopathy in Liaoning Province, China: a population-based cross-sectional study. PLoS ONE. (2015) 10:e0121477. doi: 10.1371/journal.pone.0121477

16. Srivastava KK, Kumria MM, Grover SK, Sridharan K, Malhotra MS. Glucose tolerance of lowlanders during prolonged stay at high altitude and among high altitude natives. Aviat Space Environ Med. (1975) 46:144-6.

17. Lindgärde F, Ercilla MB, Correa LR, Ahrén B. Body adiposity, insulin, and leptin in subgroups of Peruvian Amerindians. High Alt Med Biol. (2004) 5:27-31. doi: 10.1089/1527029043229 63663

18. Calderón R, Llerena LA, Munive L, Kruger F. Intravenous glucose tolerance test in pregnancy in women living in chronic hypoxia. Diabetes. (1966) 15:130-2. doi: $10.2337 /$ diab.15.2.130

19. Krampl E, Kametas NA, Nowotny P, Roden M, Nicolaides KH. Glucose metabolism in pregnancy at high altitude. Diabetes Care. (2001) 24:817-22. doi: $10.2337 /$ diacare.24.5.817

20. Zamudio S, Torricos T, Fik E, Oyala M, Echalar L, Pullockaran J, et al. Hypoglycemia and the origin of hypoxia-induced reduction in human fetal growth. PLoS ONE. (2010) 5:e8551. doi: 10.1371/journal.pone.00 08551

21. Nygren K, Hammarström A, Rolandsson O. Binge drinking and total alcohol consumption from 16 to 43 years of age are associated with elevated fasting plasma glucose in women: results from the northern Swedish cohort study. BMC Public Health. (2017) 17:509. doi: 10.1186/s12889-0174437-y

22. Bertoglia MP, Gormaz JG, Libuy M, Sanhueza D, Gajardo A, Srur A, et al. The population impact of obesity, sedentary lifestyle, and tobacco and alcohol consumption on the prevalence of type 2 diabetes: analysis of a health population survey in Chile, 2010. PLoS ONE. (2017) 12:e0178092. doi: 10.1371/journal.pone.0178092

23. Baliunas DO, Taylor BJ, Irving H, Roerecke M, Patra J, Mohapatra S, et al. Alcohol as a risk factor for type 2 diabetes: a systematic review and meta-analysis. Diabetes Care. (2009) 32:2123-32. doi: 10.2337/dc 09-0227

24. Larsen JJ, Hansen JM, Olsen NV, Galbo H, Dela F. The effect of altitude hypoxia on glucose homeostasis in men. J Physiol. (1997) 504:241-9. doi: 10.1111/j.1469-7793.1997.241bf.x

25. Stock MJ, Chapman C, Stirling JL, Campbell IT. Effects of exercise, altitude, and food on blood hormone and metabolite levels. J Appl Physiol. (1978) 45:350-4. doi: 10.1152/jappl.1978.45.3.350

26. Sawhney RC, Malhotra AS, Singh T, Rai RM, Sinha KC. Insulin secretion at high altitude in man. Int J Biometeorol. (1986) 30:231-8. doi: 10.1007/BF02189466

27. Woolcott OO, Ader M, Bergman RN. Bergman. glucose homeostasis during short-term and prolonged exposure to high altitudes. Endocr Rev. (2015) 36:149-73. doi: 10.1210/er.2014-1063 
28. Picón-Reátegui E. Effect of chronic hypoxia on the action of epinephrine in carbohydrate metabolism. J Appl Physiol. (1966) 21:1181-4. doi: $10.1152 /$ jappl.1966.21.4.1181

Conflict of Interest: The authors declare that the research was conducted in the absence of any commercial or financial relationships that could be construed as a potential conflict of interest.
Copyright $\odot 2020 \mathrm{Lin}, \mathrm{Liu}, \mathrm{Xu}$, Ning, Tu, Yang and Wang. This is an open-access article distributed under the terms of the Creative Commons Attribution License (CC $B Y)$. The use, distribution or reproduction in other forums is permitted, provided the original author(s) and the copyright owner(s) are credited and that the original publication in this journal is cited, in accordance with accepted academic practice. No use, distribution or reproduction is permitted which does not comply with these terms. 